\title{
PHARMACOVIGILANCE OF RADIOGRAPHIC CONTRAST-INDUCED ADVERSE DRUG REACTIONS IN A TERTIARY CARE HOSPITAL OF SOUTH INDIA
}

\author{
INBARAJ SD ${ }^{1 *}$, SIDHU GANESH R ${ }^{2}$, MUTHIAH NS ${ }^{1}$ \\ ${ }^{1}$ Department of Pharmacology, Sree Balaji Medical College and Hospital, Bharath University, Chromepet, Chennai - 600 0044, Tamil Nadu, \\ India. ${ }^{2}$ Department of Radiodiagnosis, Sree Balaji Medical College and Hospital, Bharath University, Chromepet, Chennai - 600 0044, \\ Tamil Nadu, India. Email: inbaraj4@yahoo.co.in \\ Received: 02 April 2017, Revised and Accepted: 20 April 2017
}

ABSTRACT

Objective: The aim of this study was to analyze the nature and incidence of adverse drug reactions (ADRs) to radiographic contrast media (oral and intravenous) reported during a 11/2 years' period in a tertiary care hospital in South India.

Methods: The study was an observational prospective study of ADRs to radiographic contrast media (oral and intravenous) observed during a period of $1 \frac{1}{2}$ years from July 2014 to October 2015 in Department of Radio Diagnosis at Sree Balaji Medical College and Hospital, Chromepet. The observations were analyzed for demographic profile, frequency, severity, causality, and temporal relationship of contrast administration to the occurrence of ADRs.

Results: A total of 33 ADRs were observed for oral and intravenous radiographic contrast media administered for radiographic study for the abovementioned period. It included 17 (51.5\%) males and 16 (48.5\%) females. Among the 33 ADRs, 19 (57\%) were for oral and intravenous radiographic contrast and 14 (42\%) for intravenous radiographic contrast alone. The most frequent ADRs were vomiting and nausea 16 (48\%), skin rashes 9 (27\%), and thrombophlebitis 9 (27\%). As per Naranjo's algorithm and WHO causality assessment, all reactions are probable except in one patient who received intravenous contrast administration was possible. According to the Hartwig severity scale, 23 (69\%) reactions were mild, 7 (21\%) reactions were moderate, and 3 (9\%) reactions were severe. There was no fatality observed. Adverse events required immediate treatment in 22 (66\%). Most of the reactions, i.e., 21 (63\%) appeared immediately after contrast administration. 12 (36\%) reactions appeared within next 30 minutes after contrast administration.

Conclusion: The common adverse reactions to radiographic contrast were mild in severity such as nausea, vomiting, skin rashes, and giddiness. Most of the reactions occur immediately after administration of contrast. The causality of majority of the ADRs is probable. Pharmacovigilance is an important tool in detection, reporting and thereby preventing ADRs due to radiographic contrast media.

Keywords: Radiographic contrast media, Adverse drug reactions, Pharmacovigilance.

(c) 2017 The Authors. Published by Innovare Academic Sciences Pvt Ltd. This is an open access article under the CC BY license (http://creativecommons. org/licenses/by/4. 0/) DOI: http://dx.doi.org/10.22159/ajpcr.2017.v10i7.18857

\section{INTRODUCTION}

In recent times, widespread daily use of contrast media for latest imaging procedures such as computed tomography (CT) and magnetic resonance imaging (MRI) has become mandatory. Hence, the incidence of adverse reactions to contrast media has increased which is not been reported to pharmacovigilance center in our country [1]. Voluntary reporting of adverse drug reactions (ADRs) has proved to be a source of valid information to pharmacovigilance program [2]. An integrated clinical, pharmaceutical, pharmacovigilance system is important in imparting accurate knowledge of ADRs to contrast media [3]. An important step in prevention of ADRs to contrast media is taking history of previous drug allergy, knowing the drug interaction to polypharmacy, especially in the elderly. Even minor adverse reactions should not be ignored as it may precipitate the risk of severe anaphylactic reaction on subsequent exposure.

Radiographic opacity of these contrast media is provided by the iodine [4]. Iodinated contrast media can be classified chemically into four categories [5]. Ionic monomers containing sodium and melamine which dissociates in solution to produce anion and cation hence they are hypertonic, for example, diatrizoate. Non-ionic monomers will not dissociate in solution and have less osmolality, for example, iohexol, iopamidol, loperamide, etc. As non-ionic dimmers, for example, iodixanol have an osmolality of 300 mosmols $/ \mathrm{kg}$ of water which is similar to the physiological osmolality of blood, they are considered as iso-osmolar contrast media [6].
Not much of study was done on the pharmacovigilance of radiographic contrast in India; hence, this study was done in a tertiary care center in South India to know the causality and severity of ADRs and also to create awareness among medical practitioners about this new area of pharmacovigilance.

\section{METHODS}

This observational study was done in the Department of Radio Diagnosis, Sree Balaji Medical College and Hospital, Chromepet, Chennai, South India. The Institutional Ethical Committee approval was obtained and the study was conducted from July 2014 to October 2015. Patients undergoing radiographic imaging with contrast media were observed and assessed for ADRs. The observations were made for demographic

Table 1: Causality of ADR due to contrast media - Naranjo's algorithm

\begin{tabular}{lll}
\hline Scale & Inference & Frequency (\%) \\
\hline 4 & Possible & $1(3.03)$ \\
5 & Probable & $12(36.3)$ \\
6 & Probable & $10(30.3)$ \\
7 & Probable & $6(18.1)$ \\
8 & Probable & $4(12.1)$ \\
Total & - & $33(100)$ \\
\hline
\end{tabular}

$\mathrm{n}=33$. ADR: Adverse drug reaction 
profile, frequency, causality, and severity of ADRs. For causality WHO causality assessment scale [7] and Naranjo's algorithm [8] were used. Hence both showed same results only Naranjo's algorithm is shown in Table 1. Modified Hartwig and Siegel scale [9] was applied to assess the severity of the reported adverse reactions.

\section{Statistical analysis}

The collected data from the observations were assessed for descriptive statistics such as frequencies and percentages. The statistical analysis was done using Microsoft Excel program 2013.

\section{RESULTS}

During July 2014 to October 2015, 1893 patients received oral and intravenous contrast media, intravenous 720 (38\%), oral and intravenous 1173 (62\%). A total of 33 ADRs were observed among which 14 (42\%) intravenous, 19 (58\%) oral and intravenous. Among the patients reported ADRs, 17 (51.5\%) were male and 16 (48.5\%) were female. The mean age of patients reported with ADR is more or less same.

As per Naranjo's algorithm and WHO causality assessment, all reactions are probable except in one patient who received intravenous contrast administration was possible in causality. Preexisting risk factors were present for $6(18 \%)$ in oral and intravenous contrast patients. Of the 33 patients, oral contrast used was gastrografin and intravenous contrast used was iopamidol. Of the 33 patients, 31 (94\%) patients undergone CT scan and only 2 (6\%) patients undergone MRI scan.

Comparison of the frequency of different ADRs between intravenous, and oral and intravenous is provided in Table 2 . The severity of the ADRs is presented for intravenous and oral and intravenous contrast as per Hartwig and Siegel severity scale in Table 3. Among the 33 patients, $23(69 \%)$ developed mild reactions, 7 (21\%) moderate reactions, and $3(9 \%)$ severe reactions. Among the 14 intravenous contrast group patients, mild reactions in $10(71 \%)$ and moderate reaction in $4(28.4 \%)$ were observed. Among the 19 intravenous and oral contrast

Table 2: Frequency of adverse events in intravenous and combined oral and intravenous contrast administered patients

\begin{tabular}{llll}
\hline ADRs & Intravenous \% & $\begin{array}{l}\text { Oral and } \\
\text { intravenous \% }\end{array}$ & $\begin{array}{l}\text { Total } \\
\mathbf{n}(\%)\end{array}$ \\
\hline $\begin{array}{l}\text { Nausea or } \\
\text { vomiting }\end{array}$ & $6(42.8)$ & $10(52.6)$ & $16(48.4)$ \\
Urticaria & $4(28.5)$ & $5(26.3)$ & $9(27.2)$ \\
Cough, sneezing & 0 & $1(5.2)$ & $1(3)$ \\
Tightness of chest & $1(7.1)$ & 0 & $1(3)$ \\
Hypotension & 0 & $1(5.2)$ & $1(3)$ \\
Facial swelling & 0 & $1(5.2)$ & $1(3)$ \\
Thrombophlebitis & $2(14.2)$ & $1(5.2)$ & $3(9)$ \\
Bronchospasm & $1(7.1)$ & 0 & $1(3)$ \\
Total & $14(100)$ & $19(100)$ & $33(100)$ \\
\hline
\end{tabular}

Sample size n=33, ADR: Adverse drug reactions group patients, mild reactions in $13(68.2 \%)$ and moderate reactions in $3(15.6 \%)$ were observed. The proportion of mild reactions was significantly higher in patients received oral and intravenous contrast $(n=13)$ than those received intravenous alone $(n=10)$. The total number of ADRs to both the 2 routes of administration was $23(69 \%)$ mild reactions and 7 (21\%) moderate reactions. When compared with the similar study done by Subathra et al. [4].

In our study, also mild ADRs are more than the moderate and severe ADRs.

The analysis of causality by Naranjo's algorithm showed all the ADRs (97\%) probable and only one ADR (3\%) was possible. While assessing the time of occurrence of ADRs and administration of contrast agent, it was found that most of the reactions (75\%) occurred immediately after intravenous contrast administration reactions $(25 \%)$ occurred in 30 minutes after administration of contrast. No contrast-induced nephropathy was reported in our study.

\section{DISCUSSION}

According to the study published in South India [4], the incidence of ADRs for contrast media is $0.34 \%$. The incidence of ADRs for non-ionic contrast was $0.78 \%$ ( 1 in 100 patients). In our study, the incidence for oral and intravenous contrast was $0.017 \%$. The overall incidence rate reported in our study is less than in other studies. This may be due to less number of patients studied. The severity of ADRs as per Hartwig and Siegel scale for mild ADRs such as nausea, vomiting, cough, and skin rashes was more $(68.2 \%)$ in oral and intravenous contrast administration than intravenous route alone. Moderate ADRs are slightly more in intravenous route $(28.4 \%)$. Overall most of the ADRs fall in the severity scale of mild-to-moderate category. Only 3 severe events $(15.2 \%)$ occurred for the combined intravenous and oral administration. The causality assessment according to Naranjo's algorithm showed the ADRs (97\%) probable and only one ADR (3\%) was possible. There are four main steps in the prevention of contrastinduced ADRs: (1) Identify patients at risk, (2) limit the usage of contrast to essential cases, (3) appropriate storage, (4) administer right dose and route, and (5) ensure adequate hydration of the patient [10]. An important step in pharmacovigilance to prevent contrast-induced ADRs is by taking family history and history of drug allergy to identify the predisposing factors. The communication technology has imparted huge benefits to pharmacovigilance system by interlinking health-care professionals, pharmacists, and patients [11]. REACT is a web-based system which can support the radiologist in preventing ADRs due to contrast media [10].

\section{CONCLUSION}

The common adverse reactions to radiographic contrast were mild in severity such as nausea, vomiting, skin rashes, and giddiness. Most of the reactions occur immediately after administration of contrast. The causality of majority of the ADRs is probable. Pharmacovigilance is an important tool in detection, reporting and thereby preventing ADRs due to radiographic contrast media.

Table 3: Severity of adverse events in intravenous and combined oral and intravenous contrast administered patients - Hartwig and Siegel scale

\begin{tabular}{|c|c|c|c|}
\hline \multirow[t]{3}{*}{ Hartwig and Siegel scale } & \multicolumn{3}{|c|}{ Number of adverse drug events n (\%) } \\
\hline & \multirow{2}{*}{$\begin{array}{l}\text { Intravenous contrast } \\
\text { Number of events }\end{array}$} & \multicolumn{2}{|l|}{ Oral and intravenous contrast } \\
\hline & & Number of events & Number of patients \\
\hline Mild & $10(71)$ & $3(68.2)$ & $23(69)$ \\
\hline Moderate & $4(28.4)$ & $3(15.6)$ & $7(21)$ \\
\hline Severe & 0 & $3(15.2)$ & $3(9)$ \\
\hline Total & $14(100)$ & $19(100)$ & $33(100)$ \\
\hline
\end{tabular}

Sample size $\mathrm{n}=33$ 


\section{REFERENCES}

1. Moride Y, Haramburu F, Requejo AA, Bégaud B. Under-reporting of adverse drug reactions in general practice. Br J Clin Pharmacol 1997;43(2):177-81.

2. Kumar L. Pharmacovigilance/reporting adverse drug reactions: An approach to enhance health surveillance and extending market share by minimizing the chances of drug withdrawals. Int J Pharm Pharm Sci 2015;7(9):1-7. July; 2015. Available from: http://www. innovareacademics.in/journals/index.php/ijpps/article/view/5387. [Last accessed on 2017 Apr 13].

3. American Society of Hospital Pharmacists. ASHP Guidelines on Adverse Drug Reaction Monitoring and Reporting: Practice Standards of ASHP 1992-1993. American Society of Hospital Pharmacists, Bethesda MD; 1992.

4. Subathra A, Sandhiya S, Kesavan R. An analysis of adverse drug reactions to radiographic contrast media reported during a 3 year period in a tertiary care hospital in south India. Indian J Physiol Pharmacol 2014;58(1):45-50.

5. Morris TW. X-ray contrast media: Where are we now, and where are we going? Radiology 1993;188(1):11-6.
6. Palkowitsch P, Lengsfeld P, Stauch K, Heinsohn C, Kwon ST, Zhang SX, et al. Safety and diagnostic image quality of iopromide: Results of a large non-interventional observational study of European and Asian patients (IMAGE). Acta Radiol 2012;53(2):179-86.

7. The Use of the WHO-UMC System for Standardized Case Causality Assessment. Available from: http://www.who-umc.org.

8. Naranjo CA, Busto U, Sellers EM, Sandor P, Ruiz I, Roberts EA, et al. A method for estimating the probability of adverse drug reactions. Clin Pharmacol Ther 1981;30(2):239-45.

9. Hartwig SC, Siegel J, Schneider PJ. Preventability and severity assessment in reporting adverse drug reactions. Am J Hosp Pharm 1992;49(9):2229-32.

10. Cecchi A, De Marco L, Chittaro L. Pharmacovigilance to reduce contrast media reactions: Hospital Pharmacy Europe May/June; 2011. Available from: http://www.hospitalpharmacyeurope.com/issue/56may-june-2011. [Last accessed on 2017 Apr 18].

11. Lua PL, Ibrahim UI. The application of communication technology in hospital and community pharmacies: A brief review. Int J Pharm Pharm Sci 2015;7(3):1-5. Jan; 2015. Available from: http://www. innovareacademics.in/journals/index.php/ijpps/article/view/4206. [Last accessed on 2017 Apr 13]. 